\title{
COMMUNITY DEMANDS AND RESOURCES AND WORK-FAMILY CONFLICT: CASE STUDY IN KUCHING SARAWAK
}

\author{
ZAITON HASSAN \\ NOR AFIZA HASNAN \\ SURENA SABIL \\ Faculty of Cognitive Sciences and Human Development \\ Universiti Malaysia Sarawak
}

\begin{abstract}
Most studies on work-life balance only examine work and family domains. While work is the only role in its domain, life consists of many aspects besides family. However, research on other roles is still very limited. This study examines the influence of community (neighbour, neighbourhood, relatives, friends), and participation in Non-Government Organisations (NGOs), demands, and resources on work-family conflict (WFC) and family-work conflict (FWC). Questionnaires were distributed to 506 employees from six public and private organisations in Kuching, Sarawak. Data were analysed using the Structural Equation Modelling (SEM) using AMOS Version 20. The findings showed that WFC was negatively related with demands from neighbours, relatives, and friends; and positively related with demands from participating in NGOs and resources from neighbours. FWC was negatively related with demands from neighbours, relatives, and friends; and positively related with resources from neighbours and relatives. This study provided evidence that community domain influences the WFC and FWC. Thus, organisations should consider the community domain in formulating strategies to minimise WFC and FWC experienced by the employees.
\end{abstract}

Keywords: Work-family conflict, family-work conflict, community demands, and resources.

\section{Introduction}

Research on work-life balance or work-family interface started as early as the 1930s (Frone, 2003) and for the past few decades, research in this area has been abundant (MacDermid, 2005). While work is seen as the only role in its domain, the life or non-work domain consists of 
a few roles, such as family, religion, community, friendship, leisure, health, social, and religious involvement (Frone, 2003). Since family plays the most important role in the life domain, the focus of research on this role is inevitable. Although it is still limited, other roles in the life domain, such as community and leisure (Kirchemeyer, 1993; Lewis, 2003; Voydanoff, 2004a) are slowly drawing more attention.

Initial evidence suggested that community, work, and family are correlated. For example, community satisfaction is positively associated with family satisfaction and marital quality (Toth, John, Brown, \& Xu, 2002; Voydanoff, 2004a). On the other hand, social incoherence and friend demands are positively related to workfamily conflict, while sense of community and support from friends have positive effects on work-family facilitation (Voydanoff, 2004a). Community also acts as resources and demands in relation to workfamily interface. Hashim (2005) in her study among middle-class Malay women in Shah Alam, Malaysia, found that nearly 50 per cent of respondents receive assistance from extended family members (mother, mother-in-law, and sisters) for childcare. In contrast, Aryee (2005) in his sub-Saharan study found that elder parents and extended family obligations are stressors to an individual. Moreover, the extended family in collectivist societies also poses a burden, such as financial obligations and maintaining harmonious lifelong relationships (Aryee, 2005; Aycan, 2008), which may not be critical in individualist societies. Thus, this study aimed to fill the gap in the literature by investigating community role in the work-family interface, particularly in work-family and family-work conflict (WFC and FWC).

Scholars had begun to consider that demands and resources other than work and family characteristics may also influence the ability of individuals and families to fulfill their work and family responsibilities (Voydanoff, 2004c). There is a growing consensus that organisations alone cannot meet the many needs of working families, especially those with children. It is time to explore the role of community not only as a context outside of work, but as a provider of resources essential to the well-being of working families (Barnett \& Gareis, 2008). A community is also part and parcel of the individual's life and the role of every community is undeniably important, especially in the Eastern context where the community is sometimes treated as part of the family.

This study is significant for two reasons. Firstly, the community domain (neighbours, neighbourhood, relatives, friends and NGO 
participation) was examined in the work-family interface. In a collectivist society, the role of relatives, neighbours, and friends may differ from the individualist society. For instance, in a collectivist society, relatives are often considered as part of the family and friends are pre-determined by family status (Hofstede \& Hofstede, 2005). Therefore they may have bigger and more significant roles in the employee's life. Secondly, this study also investigated both directions of conflict, from work to family and family to work, as espoused by the literature (Frone, 2003; Carlson, Kacmar, \& Williams, 2000), which would depict the full picture of conflict experienced by an employee, as well as the opportunity to observe how each demands and resources variables influence WFC and FWC. This would assist the organisation to design a more strategic intervention to minimise WFC and FWC, and identify resources outside the work domain to assist the employee in achieving work-life balance. Thus this study aimed to identify whether the demands and resources in a community affect the work-life conflict of employees.

\section{Community Demands and Conflict}

Community refers to the social relationship that individuals have based on group consensus, shared norms and values, common goals, and feelings of identification, belonging, and trust (Small \& Supple, 2001). Community demands and resources differ from work demands and resources in that they originate outside of the work and family domains (Voydanoff, 2004a). The community demands and resources included in this study comprise of four aspects of community: neighbors who live near or next to another, neighborhood - local community as a local geographic community, friends; who serve as a major source of primary group interaction outside the family (Voydanoff, 2004b), and relatives, who are related through kinship or marriage. They seem to provide comparable demands and resources that help or hinder individual fulfill their work and family responsibilities. Past research showed that social support outside of work, such as that provided by spouses and friends, may have a positive impact on work-family balance by reducing work-family conflict (Carlson \& Perrewe, 1999).

Voydanoff (2005) explained that community demands focus on psychological strain associated with demands from the a general community, neighbourhood, and friends. Community demands 
can be considered as strain-based conflict that focus on negative perceptions of community life that may spillover to the work-family interface. This spillover may involve the transmission of negative emotions, stress, energy depletion, and interpersonal unavailability; which would lead to WFC and / or FWC.

Similarly, perception of living in an unsafe neighbourhood is a potential stressor that may trigger strain which may spillover to work. High levels of personal and emotional demands from friends also may reduce the ability of employees to deal with the demands presented by their work, thereby increasing the likelihood of WFC and FWC. Family and community demands are positively related to FWC (Voydanoff, 2004c). High levels of personal and emotional demands from friends may reduce the ability of employees to deal with demands presented by their families and community, thereby increasing the likelihood of FWC.

Voydanoff (2005) clarified that family and community demands are relatively relevant for FWC because they are associated with processes that limit the ability of individuals to meet obligations in another domain. In her study on 2,507 employed respondents in the United States, she found that social incoherence and friend demands are positively related to WFC. Boyar, Maertz, Carl, and Pearson (2005) reported that employees in Southern United States with high kinship responsibilities (obligation to relatives living in the community) have a higher incidence of leaving their job early.

According to Core (1994), in households where both partners work, women are likely to spend about twice as much time as men on household chores. Since women have insufficient time to sufficiently perform all tasks expected of them as mothers, wives, and workers, their roles and contribution in the community are also affected. In Malaysia, the community organising role is measured by involvement in local community organisations and associations, and very few women are involved (Hashim \& Omar, 2004). Women are not able to take up the additional burden of community work due to their household chores.

In sum, community demands are relatively strongly related to workfamily and family-work conflict. Therefore, it was hypothesised that:

H1: Neighbours/neighbourhood demands are positively related to WFCl FWC. 
H2: Friend demands are positively related to WFC/FWC.

H3: Relative demands are positively related to WFC/FWC.

H4: Participation in NGOs is positively related to WFC/FWC.

\section{Community Resources and Conflict}

Community resources are aspects of social integration and similar to family integration, social integration include affective interconnectedness with others (Voydanoff, 2004b). In this study, community resources include four types of social integration; sense of community, neighborhood attachment, support from friends and support from relatives. Support from relatives is included in this study to suit Malaysian collectivist context.

Sense of community consists of four interrelated elements, which are feeling of belonging, the sense that the individual and the group matter to each other, the feeling that members' needs will be met through group resources, and a shared history (McMilan \& Chavis, 1986), as cited in Voydanoff, 2004b). Meanwhile neighbourhood attachment is associated with neighbourhood ties, trust, pride, and satisfaction (Woldoff, 2002). Support from friends and relatives are types of informal social support, which may include resources such as emotional support, instrumental support, and support in the form of advice or information.

The exchange of support is important because of the pleasure that individuals receive from contact with other people and for the sense of personal satisfaction associated with their ability to provide help to others. Family members are important parts of this exchange, but research showed that friends also play an important role (Griffith, 1985). Liebler and Sandefur (1998) also mentioned that exchanges between friends are probably more important now because of the extensive mobility of individuals away from other family members. For many individuals in our society, a friend or neighbour is likely to be more accessible in their time of need. Good relationship with friends, neighbours and the community; the involvement in the community activities, and being a part in the social activities would increase social networking. Lack of this support may lead to conflict that would influence work and family balance. 
Barnett et al. (2008) proposed that community resources may also encompass a broad array of assets or infrastructure - good schools, libraries, well-lit playgrounds, sidewalks, bike trails, community facilities for teens and elders, accessible healthcare services, safe and adequate transportation, and accessible retail business zones. Employees residing in communities with abundant resources are likely to report better quality-of-life and well-being outcomes than those residing in communities with inadequate community resources.

According to Voydanoff (2005), previous research focused more on WFC and not much study has been done on FWC. Previous research found that compared to community demands, family demands are more related to FWC (Frone, Rusell, \& Cooper, 1994). Community resources were less related to FWC (Voydanoff, 2005).

Understanding how community demands and resources combine to influence WFC and FWC provides a necessary foundation for designing work, family, and community policies and programmes that reduce WFC and FWC. Thus, it was hypothesised that:

H5: Resources from neighbours are negatively related to WFC/FWC.

H6: Resources from friends are negatively related to WFC/FWC.

H7: Resources from relatives are negatively related to WFC/FWC.

H8: Resources from neighbourhood are negatively related to WFC/FWC.

\section{Methodology}

\section{Participants}

Six public and private sectors in a diversity of industries, for examples forestry, manufacturing, telecommunication, and service industry in Sarawak, participated in this study. Respondents were contacted through their human resource managers and invited to complete the confidential survey. A cover letter attached to each questionnaire explained the objectives of the study, assured confidentiality, and the voluntary nature of the research. Questionnaires were returned after two weeks in sealed envelopes to the researcher through the human resource managers. 


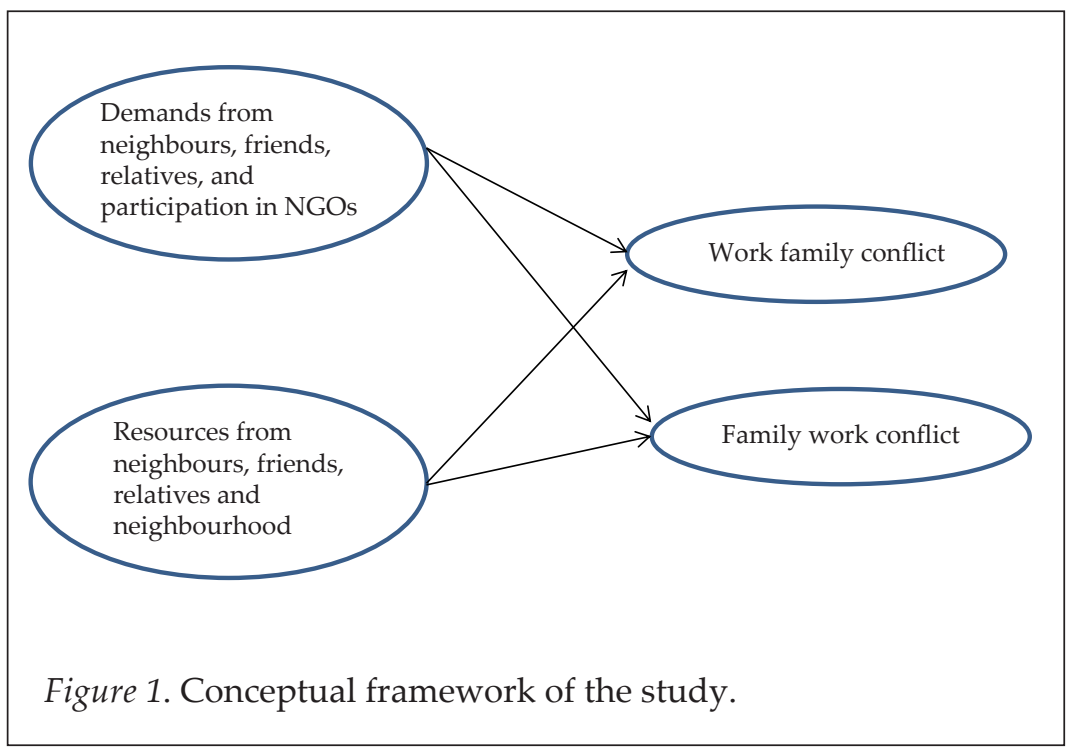

A total of 506 employees responded representing a response rate of 50.6 per cent. Over half of the respondents were male (56 per cent). The majority were non-executives (77 per cent), had permanent posts (82 per cent), were in the age group of 35 to 45 (36 per cent), were married for an average of 15 years (53 per cent) with 1 to 9 children (80 per cent), and had a working spouse (50 per cent). A total of 44 per cent were from the Malay ethnic group, 33 per cent were other Bumiputra ethnics (Iban, Melanau, Orang Ulu, and Bidayuh), and 22 per cent were Chinese. Half (50 per cent) were Muslim, 38 per cent were Christian, and 9.0 per cent were Buddhist while 39 per cent had 11 years of education with 15 per cent having a Bachelors degree.

\section{Measures}

\section{Work-Family Conflict}

Work-family conflict was measured with an instrument developed by Carlson et al. (2000). This 18-item questionnaire is scored on a fivepoint Likert scale $(1=$ strongly disagree, $5=$ strongly agree $)$. An example item for WFC is "My work keeps me from my family activities more than I would like" and FWC "Due to stress at home, I am often preoccupied with family matters at work". Higher scores indicate 
more WFC. Cronbach alpha for WFC and FWC were 0.86 and 0.85 respectively.

\section{Community Demands}

Community demands refer to demands from neighbours, relatives, friends and participation in NGO. Demands from neighbours and friends were measured using the demands from friends scale (Voydanoff, 2004a). Four items in each component were scored on a four-point scale $(1=n e v e r)$ to $(4=$ always $)$. Example items include "How often do they (friends) make too many demands on you", "How often do they (neighbours) let you down when you are counting on them" and "In relationship with your relatives, it robbed you the energy required to do your job". All scores were summed and higher scores could indicate higher demands $(\alpha=0.77)$. The fourth component of community demands was measured by time spent in NGO (political, neighbourhood, and religious activities) (Voydanoff, 2004a). The score ranged from 1 (never) to 4 (several times a month). The internal reliability was 0.78 for the current study.

\section{Community Resources}

Community resources include support from relatives, neighbours, sense of neighbourhood, and friends. Score for support for relatives and neighbours ranged from 1 (not all the time) to 4 (a lot). Support from relatives was measured using four items adapted from the support from friends scale (Voydanoff, 2004a), where "relatives" replaced the word "friends". An example item includes "I can rely on my relatives for help if I have a serious problem". Support from neighbours was assessed using three items from the neighborhood attachment scale and three items from sense of community (Voydanoff, 2004a). Example items are "I feel very good about my neighbourhood" and "I feel close to other people in my community".

A 20-item Perceived Support from Friends (PSS-Fr) questionnaire (Procidano \& Heller, 1983) was used to assess support from friends. Example items are "My friends give me the moral support that I need" and "My friends enjoy hearing about what I think". The PSSFr has three possible answers: 0 (don't know), 1 no), and 2 yes). Higher scores would indicate more perceived support being received from the friends $(\alpha=0.82)$. 


\section{Analysis}

\section{Analytical Strategy}

First, the confirmatory factor analysis (CFA) was performed, followed by correlation and hypotheses testing. CFA and hypotheses testing were examined by structural equation modeling (SEM) using AMOS 20.0 through maximum likelihood estimation procedure.

The measurement model was examined for each latent measure. For demands, the four-factor model with correlations between factors was found to provide a reasonable fit to the data and better than a one-factor model of demands. For resources, the four-factor model with correlations between factors was found to provide a reasonable fit to the data and better than the one-factor model of resources.

Harman's one factor test using factor analysis was conducted to test the presence of common method variance and the analysis revealed that more than one single factor exist. Different scales were used in the questionnaires to address the common method variance.

\section{Results}

Using Pearson Corelation, it was found that resources were negatively related to WFC and FWC, and demands were positively related to WFC and FWC. In other words, higher resources (support) would decrease conflict; while higher demands would increase conflict, which is consistent with previous findings.

Table 1 shows results of hypotheses testing through SEM using AMOS version 20 . The structural model fits the data moderately; with chisquare $(x=132.972, p<0.000, \mathrm{CMIN} / \mathrm{df}=2 / 792 . \mathrm{GFI}=0.825, \mathrm{CFI}=$ $0.801, \mathrm{TLI}=0.795, \mathrm{RMSEA}=0.060$ and $\mathrm{AIC}=326.97)$.

WFC was positively related to demands from neighbour $(\beta=0.128, p<$ $0.05)$, demands from relatives $(\beta=0.102, \mathrm{p}<0.05)$, and demands from friends $(\beta=0.169, p<0.01)$. WFC was negatively related to demands from participation in NGOs $(\beta=-0.110, p<0.05)$ and resources from neighbour $(\beta=-0.125, p<0.005)$. Meanwhile, FWC was positively related to demands from neighbour $(\beta=0.104, p<0.05)$, relatives $(\beta=$ 
IJMS 21 (1), 111-126 (2014)

$0.157, p<0.01)$, and friends, $(\beta=0.169, p<0.001)$ and resources from relatives $(\beta=0.102, p<0.05)$. FWC was negatively related to resources from neighbors $(\beta=-115, \mathrm{p}<0.01)$.

Table 1

Results of Hypothesis Testing using SEM

\begin{tabular}{llll}
\hline & & $p$ & $\beta$ \\
\hline Demands neighbour & $->$ WFC & $.017^{*}$ & .128 \\
Demands relatives & $->$ WFC & $.045^{*}$ & .102 \\
Demands friends & $->$ WFC & $.002^{* *}$ & .169 \\
Demands NGO & $->$ WFC & $.034^{*}$ & -.110 \\
Demands neighbour & $->$ FWC & $.029^{*}$ & .104 \\
Demands relatives & $->$ FWC & $.001^{* * *}$ & .157 \\
Demands friends & $->$ FWC & $.001^{* * *}$ & .169 \\
Demands NGO & $->$ FWC & .213 & -.115 \\
Resources neighbour & $->$ WFC & $.019^{* *}$ & -.126 \\
Resources relatives & $->$ WFC & .608 & .026 \\
Resources friends & $->W F C$ & .510 & .036 \\
Resources sense of neighbourhood & $->$ WFC & .466 & .034 \\
Resources neighbour & $->$ FWC & $.019^{* *}$ & -.115 \\
Resources relatives & $->$ FWC & $.030^{*}$ & .102 \\
Resources friends & $->$ FWC & .073 & .090 \\
Resources sense of neighbourhood & $->$ FWC & .161 & -.060 \\
\hline
\end{tabular}

Notes. ${ }^{*} p<0.05,{ }^{* *} p<0.01,{ }^{* * *} p<0.001$.

\section{Discussion}

The present study makes an important contribution to the worklife balance literature. Although several Malaysian researchers had studied work-family conflict (Ahmad, 1996; Noor, 2006), the present study is one of the first to provide empirical evidence on the influence of community demands and resources on WFC and FWC.

The findings have important implications for work-family interface research. This study confirmed that community demands and resources function similar to work and family demands and resources. The finding also strengthens the universality of the relationship between demands and conflict. In this study it was found that community demands (neighbours, relatives, and friends) would 
increase WFC, and FWC while support from neighbours would reduce $W F C$ and FWC.

Although in general demands lead to conflict, not all demands trigger conflict. In this study, it was found that more participation in NGOs would lead to reduced WFC. This finding lends support to Compensation Model (O'Driscoll, 1996), which postulated that if demands or satisfaction is lacking in one domain (e.g., work domain), it can be made up by getting involved in the other domains (e.g., community domain). Involvement in NGOs can be seen as a reward or made up in another domain, because their participation leads to satisfaction. These rewards encompass privileges, status security and enhancement, and personality enrichment. Reward also includes psychological resources that are associated with feeling esteemed and valued, as well as intrinsic reward such as meaningful activities. Thus, involvement in NGOs contributed to less experience of WFC.

Support from neighbours lead to reduced WFC and FWC. The result is in agreement with Global Leadership and Organisational Behaviour Effectiveness (GLOBE) study in Malaysia that indicated Malaysians are a collectivist and caring society (Javidan \& House, 2001). This is consistent with the teachings of Islam that emphasised on solidarity and sense of belonging. Our Malaysian collectivist culture that keeps helping each other would influence how resources from a neighbour is able to decrease FWC. For example, an individual can ask their neighbours to look after their home or take care of their children during working hours. It is proposed that these resources would increase the capacity of individuals and families to fulfill their work and family responsibilities so that WFC and FWC is decreased (Voydanoff, 2005).

Interestingly resources from relatives have a positive relationship with FWC. In other words, higher support from relatives lead to higher levels of FWC. One possible explanation is that although relatives offer unique support such as childcare and performing household chores, that support also generates reciprocal expectations which create additional responsibilities. Financial burden, caring responsibilities, and maintaining lifelong harmonious relationships with extended families and relatives are among the major sources of conflict for collectivist societies (Aryee, 2005; Aycan, 2008). Previous study found that caring for relatives and friends is the highest 
demand for working women in Malaysia (Choi, 2005). This reciprocal relationship may contribute to FWC.

\section{Implication and Recommendation}

Pitt-Catsouphes and Christensen (2004) suggested that work-family issues should be considered community issues, as the community can provide assistance or hindrance beyond work and family in achieving work-life balance. This study is evidence that the community influences work-family conflict. While it is important to offer a family-friendly policy targeted at individual employees to decrease work-family conflict, organisations could also participate in community programmes at the neighbourhood level. Since support from neighbours can reduce conflict, organisations could sponsor activities designed to strengthen relationships among neighbours, such as cleanliness programmes, community child care, and tuition classes for school children. The current neighbourhood programmes available in Malaysia, for example Neighbourhood Watch (Rukun Tetangga, RELA) could be expanded to build strong relationships between neighbours and neighbourhoods, which could ultimately benefit the workplace.

The organisation should collaborate with NGOs or encourage employees to join NGOs of their choice. By joining the activities, it could be an avenue from releasing their stress at work or home, which then leads to decreased WFC and FWC.

To manage relatives effectively, regular training at the workplace such as assertiveness training, interpersonal communication, and stress management skills, could also be applied in dealing with relatives. Better relationship management with relatives could assist in decreasing FWC.

\section{Limitation and Future Research}

This study utilised cross-sectional design, which may be subjected to common method variance and does not allow us to draw conclusions about causality between independent and dependent variables. However, the Harmann one factor test was conducted to reveal that more than one factor existed for this study. Different Likert Scales were also used in administering the questionnaires. Thus, these two 
steps could reduce the effect of common method variance. Using longitudinal designs in future research would rectify this limitation.

In the work-family interface, the community could be viewed from an infrastructure and a social relationship perspective (Hill, Grzywacz, Allen, Blanchard, Matz-Costa, \& Shulkin, 2008). In this study, only community from a social relationship perspective was investigated. Community infrastructure refers to the physical context of a community, which includes childcare service, transportation systems, availability of utility services (Hill et al., 2008) that could hinder or provide opportunity for conflict, which could be examined in future research.

Future research could also investigate the positive side of the workfamily interaction - work-family enrichment, as recent studies demonstrated the benefits of work-family interface (Voydanoff, 2004c). Additionally, since life domains encompass other domains besides family, future studies could examine the influence of leisure and personal time on the work-life equation, so that a more holistic understanding of work-life balance can be understood.

\section{Conclusion}

The findings confirmed that community demands and resources function almost similar to work and family demands and resources. Higher demands usually increase conflict, while higher resources usually decrease conflict. Interestingly, this study found some exceptions. High participation in NGOs (demand) would reduce WFC, and high support (resources) from relatives would increase FWC. The collectivist characteristics of the respondents may contribute to this contradictory findings. In sum, demands and resources from neighbours play an important role in influencing both WFC and FWC. Therefore, the community domain alongside the work and family domains should be examined to further the understanding of the work-life interface.

\section{References}

Aryee, S. (2005). The work-family interface in urban Sub-Saharan Africa: A theoretical analysis. In S. A. Y. Poelmans (Ed.), Work and family: An international research perspective. (pp. 261-286). Mahwah, New Jersey: Lawrence Erlbaum. 
Ahmad, A. (1996). Work-family conflict among married professional women in Malaysia. Journal of Social Psychology, 136, 663-665.

Aycan, Z. (2008). Cross-cultural approaches to work-family conflict. In K. Korabik, D. S. Lero \& D. L. Whitehead (Eds.), Handbook of work-family integration: Research, theory and best practices (pp. 353-370). Boston: Academic Press, Elsevier.

Barnett, R. C., \& Gareis, K. C. (2008). Community: The critical missing link in work-family research. In A. Marcus-Newhall, D. F. Halpern \& S. J. Tan (Eds.), Changing realities of work and family: A multidisciplinary approach. Mahwah: Erlbaum.

Boyar, S. L., Maertz, J., Carl, P., \& Pearson, A. W. (2005). The effects of work-family conflict and family-work conflict on non attendance behaviors. Journal of Business Research, 58, 919-925.

Carlson, D. S., \& Perrewe, P. L. (1999). The role of social support in the stressor-strain relationship: An examination of work-family conflict. Journal of Management, 25, 513-540.

Carlson, D. S., Kacmar, K. M., \& Williams, L. J. (2000). Construction and initial validation of a multidimensional measure of workfamily conflict. Journal of Vocational Bahaviour, 6(2), 249-276.

Choi, B. C. K. (2005). An international comparison of women's occupational health issues in the Philippines, Thailand, Malaysia, Canada, Hong Kong and Singapore: The CIDASEAGEP study. Occupational Medicine, 55, 515-522.

Core, F. (1994), Women and the restructuring of employment. OECD Observer, 186, 5-12.

Griffith, J. (1985). Social support providers: Who are they? Where are they met? And the relationship of network characteristics to psychological distress. Basic and Applied Social Psychology, 6(1), 41-60.

Frone, M. R. (2003). Work-family balance. In J. C. Quick \& L. E. Tetrick (Eds.), Handbook of occupational health psychology (pp. 143-162). Washington D.C.: American Psychological Association.

Frone, M. R., Rusell, M., \& Cooper, M. L. (1994). Relationship between job and family satisfaction: Causal or noncausal covariation? Journal of Management, 20, 565-579.

Hashim, H. (2005). Urbanization and women: A case of middle class Malays in Shah Alam. Malaysian Journal of Social Policy and Society, 1, 139-152.

Hashim, H., \& Omar, R. (2004). Career, family and community: The dilemma of professional and semi-professional Malay women. Asian Women 2004, 19, 45-68. 
Hill, J. E., Grzywacz, J. G., Allen, S., Blanchard, V. L., Matz-Costa, C., \& Shulkin, S. (2008). Defining and conceptualizing workplace flexibility. Community, Work \& Family, 11, 149-163.

Hofstede, G., \& Hofstede, G. J. (2005). Cultures and organisations: Software of the mind. New York: McGraw-Hilll.

Javidan, M., \& House, R. J. (2001). Cultural acumen for the global manager: Lessons from Project GLOBE. Organizational Dynamics, 29(4), 289-305.

Kirchmeyer, C. (1993). Nonwork-to-work spillover: A more balanced view of the experiences and coping of professional women and men. Sex Roles, 28, 531-552.

Lewis, S. (2003). The integration of paid work and the rest of life. Is post-industrial work the new leisure? Leisure Studies, 22, 343345.

Liebler, C. A., \& Sandefur, G. D. (1998). Exchanging social support with friends, neighbours and coworkers. Center for Demography \& Ecology, University of Wisconsin-Madison. CDE Working Paper No. 98-19.

MacDermid, S. M. (2005). (Re)considering conflict between work and family. In E. E. Kossek \& J. S. Lambert (Eds.), Work and life integration: Organizational, cultural and individual perspectives (pp. 19-40). Mahwah, New Jersey: Lawrence Erlbaum.

McMilan, D. W., \& Chavis, D. M. (1986). Sense of community. American Journal of Community Psychology, 27, 75-105. Router (Eds), Does it take a village? (pp. 161-173). Mahwah, New Jersey: Lawrence Erlbaum.

Noor, N. M. (2006). Locus of control, supportive workplace policies and work-family conflict. Psychologia, 49, 48-60.

O'Driscoll, M. (1996). The interface between job and off-job roles: enhancement and conflict. In C. Cooper \& I. Robertson (Eds.), International review of industrial and organizational psychology (pp. 279-306). Chichester: John Wiley \& Sons.

Pitt-Catsouphes, M., \& Christensen, K. (2004). Unmasking the taken for granted. Community, Work \& Family, 7, 123-142.

Procidano, M. E., \& Heller, K. (1983). Measures of perceived social support from friends and from family: Three validation studies. American Journal of Community Psychology, 11, 1-24.

Small, S., \& Supple, A. (2001). Communities as system: Is a community more than the sum of its parts? In a Booth \& A. C. Crouter (Eds.), Does it take a village? (pp. 161-173). Mahwah, NJ: Lawrence Erlbaum.

Toth, J., John F., Brown, R. B., \& Xu, X. (2002). Separate family and community realities? An urban rural comparison of the 
IJMS 21 (1), 111-126 (2014)

association between family life satisfaction and community satisfaction. Community, Work \& Family, 5, 181-202.

Voydanoff, P. (2004a). Implications of work and community demands and resources for work-to family conflict and facilitation. Journal of Occupational Health Psychology, 9, 275-285.

Voydanoff, P. (2004b). The effect of work and community resources and demands on family integration. Journal of Family and Economic Issues, 25, 6-23.

Voydanoff, P. (2004c). The effect of work demands and resources on work-to family conflict and facilitation. Journal of Marriage and Family, 66, 398-412.

Voydanoff, P. (2005). The different salience of family and community demands and resources for family-to-work conflict and facilitation. Journal of Family and Economic Issues, 26(3), 395-417

Woldoff, R. A. (2002). The effect of local stressors on neighborhood attachment. Social Forces, 31, 87-116. 